\title{
Osteogenic Activity of Lupeol Isolated from Clinacanthus nutans Lindau: Activity and Mode of Action
}

\author{
Minh T. H. Nguyen, ${ }^{1}$ Quang V. Ngo, ${ }^{2}$ Huyen T. T. Nguyen, ${ }^{1}$ Quan M. Pham $\left(\mathbb{D},{ }^{3,4}\right.$ \\ Trang H. Dinh, ${ }^{1}$ Huong T. T. Nguyen, ${ }^{5}$ Nguyen V. Tinh, ${ }^{6}$ and Phuong T. M. Nguyen $\mathbb{D}^{4,7}$ \\ ${ }^{1}$ University of Science and Technology of Hanoi, Vietnam Academy of Science and Technology, 18 Hoang Quoc Viet Road, \\ Hanoi, Vietnam \\ ${ }^{2}$ Institute of Chemistry, Vietnam Academy of Science and Technology, 18 Hoang Quoc Viet Road, Hanoi, Vietnam \\ ${ }^{3}$ Institute of Natural Products Chemistry, Vietnam Academy of Science and Technology, 18 Hoang Quoc Viet Road, \\ Hanoi, Vietnam \\ ${ }^{4}$ Graduate University of Science and Technology, Vietnam Academy of Science and Technology, 18 Hoang Quoc Viet Road, \\ Hanoi, Vietnam \\ ${ }^{5}$ Institute of Ecology and Biological Resources, Vietnam Academy of Science and Technology, 18 Hoang Quoc Viet Road, \\ Hanoi, Vietnam \\ ${ }^{6}$ Vinmec Healthcare System, 458 Minh Khai Street, Vinh Tuy, Hai Ba Trung, Hanoi, Vietnam \\ ${ }^{7}$ Institute of Biotechnology, Vietnam Academy of Science and Technology, 18 Hoang Quoc Viet Road, Hanoi, Vietnam
}

Correspondence should be addressed to Phuong T. M. Nguyen; phuongnguyen@ibt.ac.vn

Received 1 June 2021; Revised 24 August 2021; Accepted 26 August 2021; Published 22 September 2021

Academic Editor: Wagdy Eldehna

Copyright $\odot 2021$ Minh T. H. Nguyen et al. This is an open access article distributed under the Creative Commons Attribution License, which permits unrestricted use, distribution, and reproduction in any medium, provided the original work is properly cited.

\begin{abstract}
Clinacanthus nutans Lindau has been traditionally used for healing of bone fragility, but the mechanism of actions has not been clarified yet. In this study, the bone regeneration activity of lupeol derived from C. nutans was assessed using an in vitro model of osteoblast cells MC3T3-E1. The finding revealed that the compound was not significantly toxic to osteoblast cells at concentration of $\leq 40 \mu \mathrm{g} / \mathrm{mL}$. Lupeol demonstrated the osteogenic activity through enhancement of alkaline phosphatase (ALP) of osteoblast cells up to $31.2 \%, 21 \%$, and $12 \%$ at concentrations of 5,10 , and $20 \mu \mathrm{g} / \mathrm{mL}$, respectively $(p<0.05)$. Besides, the mineralization activity was increased up to $170,230,185$, and $117 \%$ at concentration of $5,10,20$, and $40 \mu \mathrm{g} / \mathrm{mL}$, respectively $(p<0.05)$. The marker genes related to osteoblast differentiation evaluated on the expression level in the presence of lupeol, including collagen I (col 1), osteopontin (opn), osterix (osx), and runx2, showed upregulated expression in all the test genes $(p<0.05)$. The Western blot analysis demonstrated a clear effect of lupeol on expression of p38/p-p38, and ERK/p-ERK proteins involved in the MAPK signaling pathway. Thus, lupeol isolated from C. nutans exhibited the osteogenic activity by enhancing expression of important markers of osteogenesis, as well as affected the MAPK signaling pathway relating to osteoblast differentiation. This is the first report on the detailed mechanism of action of lupeol on bone regeneration and also explains for the traditional use of this medicinal plant for bone healing.
\end{abstract}

\section{Introduction}

Osteoporosis is a common global disease; over 200 million people worldwide suffer from this public health problem, especially women and aged people $[1,2]$. The use of current chemical medications to treat osteoporosis may cause side effects, such as stomachache, dizziness, and vomiting
$[1,3,4]$. Therefore, natural substances that are able to treat osteoporosis effectively to maintain bone strength with fewer unwanted effects that are promising alternatives.

Plant is rich in secondary metabolites; therefore, it will be a potential source for isolation of novel and effective osteogenic agents capable of inducing osteoblast differentiation and, consequently, enhancing new bone regeneration $[1,4]$. 
Clinacanthus (C.) nutans Lindau is a flowering plant in the Acanthaceae family. The plant has been used as an herbal medicine in Asian countries [5-7]. It is considered as the main cure for skin inflammation and lesion caused by virus, such as hepatitis and herpes viruses [8], or anticancer [5, 9]. It is also a traditional herbal medicine in Vietnam to treat bone fractures. The chemical compositions of this plant were investigated and classified in various groups of phytochemicals, including flavonoids, steroids, triterpenoids, cerebrosides, glycoglycerolipids, glycerides, and sulfurcontaining glycosides [10-12]. Although C. nutans has been used to heal broken bones, its mechanism for the bone healing activity has not been clarified yet. Thus, C. nutans may contain substances capable of inducing new bone regeneration. In this study, the osteogenic activity of lupeol, a major natural compound isolated from this plant, was intensively investigated to confirm its traditional uses.

\section{Experimental Section}

2.1. Materials and Reagents. The whole C. nutans plant was collected in Dalat province in September, 2018, and identified by Dr. Nguyen Thi Thanh Huong. The voucher specimen (CNL92018) was deposited at the Institute of Ecology and Biological Resource, Vietnam Academy of Science and Technology, Hanoi, Vietnam.

The preosteoblast cells MC3T3-E1 were obtained from American Type of Culture Collection (ATCC) (Manassas, VA, USA). Minimum essential medium alpha (MEM $\alpha$ ) was obtained from Gibco BRL, Life Technologies (USA). MTT (3(4,5-dimethyl-2-yl)-2,5-diphenyltetrazolium bromide) reagent, trypsin-EDTA, penicillin/streptomycin, p-nitrophenyl phosphate (pNPP) substrate, ascorbic acid, dexamethasone, $\beta$-glycerol phosphate, and fetal bovine serum (FBS) were purchased from Sigma-Aldrich (St. Louis, MO, USA). Other chemicals and reagents were of analytical grade.

2.2. Isolation of Lupeol. Our previous study indicated that the ethyl acetate (EtOAc) fraction of C. nutans showed the strongest osteogenic activity in MC3T3-E1 cells [13]. Therefore, the active compounds in this fraction were isolated for further bioactive examination. The plant material $(3 \mathrm{~kg})$ was dried and grounded to a fine powder and then macerated in $96 \% \mathrm{EtOH}$ at room temperature for $72 \mathrm{~h}(3 \times 3 \mathrm{~L})$ to obtain the ethanol residue ( $47.65 \mathrm{~g}$ ) after removing the solvent under reduced pressure. The residue was suspended in $\mathrm{H}_{2} \mathrm{O}$ and then partitioned with EtOAc $(3 \times 3 \mathrm{~L})$. The extract was concentrated under reduced pressure to yield EtOAc residue $(11.26 \mathrm{~g})$. The obtained residue was then subjected to a silica gel column chromatography (CC) using a solvent system of n-hexane:acetone $5: 1 \quad(\mathrm{v} / \mathrm{v})$ to obtain six fractions (F1.1-F1.6). The fraction F1.2 was further applied to CC using the solvent system of n-hexane: ethyl acetate $7: 1(\mathrm{v} / \mathrm{v})$ to obtain 4 subfractions (F2.1-F2.4). Lupeol was obtained from subfraction F2.2 as crystals and further purified by recrystallization using $\mathrm{MeOH} / \mathrm{H}_{2} \mathrm{O}(1: 1, \mathrm{v} / \mathrm{v})$. Chemical structure was elucidated by the analysis of NMR and MS data combined with the references.
2.3. Cell Culture and Cell Viability Assay. Cells were cultured in MEM $\alpha$ containing $10 \% \mathrm{FBS}$ and antibiotics at $37^{\circ} \mathrm{C}$ in a $5 \% \mathrm{CO}_{2}$-humidified incubator. To induce osteogenic differentiation in MC3T3-E1 cells, culture media were changed to the ODM medium (MEM $\alpha$ supplemented with $50 \mu \mathrm{g} / \mathrm{mL}$ ascorbic acid, $10^{-8} \mathrm{M}$ dexamethasone, and $10 \mathrm{mM} \beta$-glycerolphosphate). Cells were seeded at concentration of $1 \times 10^{4}$ cells/well in a 96-well plate. They were incubated with different concentrations of lupeol for $96 \mathrm{~h}$ (4 days). The cells were then incubated with a final concentration solution of $0.5 \mathrm{mg} / \mathrm{mL} \mathrm{MTT}$ for $4 \mathrm{~h}$ at $37^{\circ} \mathrm{C}$ in $5 \% \mathrm{CO}_{2}$ condition. The formazan crystals were then solubilized in dimethyl sulfoxide (DMSO), and the optical density was measured by monitoring the signal at $570 \mathrm{~nm}$ using a microplate reader (PowerWave XS model, BioTek Instruments, Inc., Winooski, VT, USA). The untreated cells were used as the control.

2.4. Alkaline Phosphatase (ALP) Activity. To evaluate the ALP activity, cells were seeded into 96-well plates in the ODM medium supplemented with $10 \%$ FBS. The culture medium was then replaced by a new ODM medium supplemented with/without the agent to be tested and incubation continued for 7 days. Cells were then rinsed with phosphate-buffered saline (PBS), and $100 \mu \mathrm{L}$ pNPP was added in the reaction. Finally, the ALP activity was measured at $405 \mathrm{~nm}$ using a spectrophotometer (Evolution $201 \mathrm{UV}$ Vis, Thermo Scientific).

2.5. Mineralization. The level of mineralization was determined using the alizarin red-S staining method in the 6-well plates for 21 days. The stained cells indicate mineralization formation. MC3T3-E1 cells were cultured in the MEMa medium containing vitamin $\mathrm{C}(50 \mu \mathrm{g} / \mathrm{mL})$ and $\beta$-glycerolphosphate $(10 \mathrm{mM})$ for 3 weeks with/without the appropriate concentration of the sample to be investigated. After that, the cells were washed twice with PBS, fixed with $70 \%$ ethanol (v/v) for $1 \mathrm{~h}$, dried in air, then stained with $40 \mathrm{mM}$ alizarin red-S ( $\mathrm{pH} 4.2$ ) for 1 hour, and thoroughly washed with water. The cells were then destained for 15 minutes with $10 \%$ cetylpyridium chloride in $10 \mathrm{mM}$ sodium phosphate buffer (pH 7.0). The optical densities (OD) were measured at $562 \mathrm{~nm}$ to determine the degree of cell staining in the samples.

2.6. $q R T-P C R$. Osteoblast cells were cultured in 6-well plates at a density of $5 \times 10^{5}$ cells $/ \mathrm{mL}$ in each well. Cells were treated with different concentrations of the sample for 3 days before RNA extraction using TRIzol reagent (Invitrogen, Life Technology). RNA concentration and RNA purity were quantified by using NanoDrop (NanoDrop ND-1000, ThermoScientific). cDNA synthesized using the superscript VILO MasterMix kit (Invitrogen, Thermo Fisher Scientific, Netherlands). The composition of cDNA synthesis contains $1 \mu \mathrm{g}$ of RNA and $4 \mu \mathrm{L}$ of master mix VILO, and RNase-free water was added to final volume of $20 \mu \mathrm{L}$. The primer sequences for marker genes using qRT-PCR including runx2, osx, opn, col 1, and house-keeping gene GAPDH as a control 
are given in Table 1. Quantitative real-time PCR was performed using SYBR green PCR master mix (NEB, US) and analyzed by the relative quantification method.

2.7. Western Blot. The effect of lupeol on the MAPK pathway relating to bone remodeling was carried out using Western blot compared to $\beta$-actin as a control. To perform the experiment, the cells were cultured and treated with/without the samples, and then, protein was extracted. Briefly, osteoblast cells were cultured in 6-well plates at a density of $5 \times 10^{5}$ cells $/ \mathrm{mL}$ in each well. Cells were treated with a selected concentration of $10 \mu \mathrm{g} / \mathrm{mL}$ lupeol before protein extraction. Cells were lysed in RIPA buffer containing $50 \mathrm{mM}$ Tris- $\mathrm{HCl}$ ( $\mathrm{pH}$ 7.5), 0.4\% Nonidet P-40, $120 \mathrm{mM}$ $\mathrm{NaCl}, 1.5 \mathrm{mM} \mathrm{MgCl}_{2}, 2 \mathrm{mM}$ phenylmethylsulfonyl fluoride, $80 \mu \mathrm{g} / \mathrm{mL}$ of leupeptin, $3 \mathrm{mM} \mathrm{NaF}$, and $1 \mathrm{mM} \mathrm{DTT}$ at $4^{\circ} \mathrm{C}$ for 30 minutes. The protein concentration was determined by the Bradford method.

For the Western blot analysis, protein extracts $(20 \mu \mathrm{g})$ were separated by $10 \%$ sodium dodecyl sulfate-polyacrylamide gel electrophoresis (SDS-PAGE) and transferred onto a PVDF membrane (Amersham Pharmacia Biotech., England, UK). This membrane was incubated with $3 \%$ bovine albumin serum (BSA) before incubation with the tested primary antibodies p38, p-p38, ERK, and p-ERK (Sigma, US) diluted $1: 1000$ overnight at $4^{\circ} \mathrm{C}$. Then, the membrane was washed and incubated with the horseradish-peroxidaseconjugated secondary antibodies $(1: 3000)$ at room temperature. The immune-reactive proteins were detected using the chemiluminescent ECL assay kit [14].

2.8. Statistical Analysis. The data were statistically analyzed using the $t$-test or ANOVA. The difference between the samples was considered to be significant when the $p$ value is $<0.05$.

\section{Results}

3.1. Isolation of Lupeol. Lupeol was isolated from the EtOAc fraction of $C$. nutans using repeated silica gel chromatography combined with a crystallization procedure as described in Figure S1 to yield lupeol as white crystals, and its molecular formula was determined to be $\mathrm{C}_{30} \mathrm{H}_{50} \mathrm{O}$ by $\mathrm{HR}$ ESI-MS at $\mathrm{m} / \mathrm{z} 427.3940[\mathrm{M}+\mathrm{H}]^{+}$with error of $0.09 \mathrm{ppm}$ (Calcd. for $\mathrm{C}_{30} \mathrm{H}_{51} \mathrm{O}^{+1}$ : 427.39344). The ${ }^{1} \mathrm{H}$ and ${ }^{13} \mathrm{C} \mathrm{NMR}$ spectra analyses data of the isolated compound presented in Table 2 and Figure S2, when compared to the reference [15], confirmed it was lupeol (Figure 1). Additionally, a relatively large peak at $\mathrm{m} / \mathrm{z} 427.3940$ in a high-resolution positive MS supports the lupeol assignment (Figure S3).

3.2. Cell Cytotoxicity. The cell viability results (Figure 2) showed that lupeol at the test concentrations did not affect the cell survival in vitro. Therefore, the concentrations 5,10 , 20 , and $40 \mu \mathrm{g} / \mathrm{mL}$ were selected for further examination of the effects on cell differentiation.
3.3. Effects of Lupeol on the ALP Activity of Osteoblasts. Alkaline phosphatase (ALP) is an early marker of osteoblast differentiation. The results presented in Figure 3 show that lupeol increased the ALP activity by $31.2 \%$ at concentration as low as of $5 \mu \mathrm{g} / \mathrm{mL}$. At concentrations of 10 and $20 \mu \mathrm{g} / \mathrm{mL}$, the activity was enhanced up to $21 \%$ and $12 \%$, respectively. However, the activity was slightly reduced but not a statistically significant difference compared to the control at a concentration of $40 \mu \mathrm{g} / \mathrm{mL}(p>0.05)$.

3.4. Effects of Lupeol on the Mineralization Activity of MC3T3E1 Osteoblast Cells. The matrix mineralization is the final stage in bone-forming cell differentiation. When mineralization is completed, calcium deposition (bone mineralization) can be seen by using the alizarin red-S staining method. The results obtained in Figure 4 show that lupeol strongly enhanced mineralization up to $170,230,185$, and $117 \%$ at concentration of $5,10,20$ and $40 \mu \mathrm{g} / \mathrm{mL}$, respectively. The histochemical staining for mineral deposition in Figure 5 confirmed this activity of lupeol.

3.5. Effects on Gene Expression. In this study, several marker genes for osteoblast differentiation were selected, including opn (a marker gene for early stage of matrix mineralization), osx (a marker gene for matrix maturation), col I (a marker gene for osteoblast differentiation and abundant expression in bone matrix), and runx2 (a marker gene for expression of a major transcription factor). The expressions were normalized to that of the house-keeping gene GAPDH. The obtained results indicated that all the test genes showed an enhanced expression up to $2.2,5.4,2.8$, and 4.1 folds at the lupeol concentration of $10 \mu \mathrm{g} / \mathrm{mL}$, respectively $(p<0.05)$ (Figure 6).

3.6. Western Blot Analysis. The ERK (extracellular signalregulated kinase) and $\mathrm{p} 38$ are mitogen-activated protein (MAP) kinases in a group of signaling molecules that appear to play important roles in the osteoblast differentiation process. In this experiment, ERK/p-ERK and p38/p-p38 were selected for examination of protein expression in the presence of $10 \mu \mathrm{g} / \mathrm{mL}$ lupeol, at which the best of mineralization levels and marker gene expressions was found. As shown in Figure 7(a), lupeol clearly induced expression of phosphorylated forms p-pERK and p-p38 under the treatment condition compared to the control. The quantification result of Western blot image using Image software (Figure 7(b)) confirmed the upregulation of protein kinase expressions.

\section{Discussion}

Since the use of current synthetic drugs to treat osteoporosis has some limitations and causes undesirable side effects for long term use, natural substances, especially those from medicinal plants that have been traditionally used for osteoporosis and osteoarthritis treatment, have been intensively investigated. In this study, the effect of natural 
Table 1: Primer sequences of study genes.

\begin{tabular}{lrr}
\hline Gene & Primer forward & Primer reverse \\
\hline runx2 & $5^{\prime}$-CCAGATGGGACTGTGGTTACC-3' \\
osx & $5^{\prime}$-TTTCAGCCCCCAAAACCATGGG-3' & $5^{\prime}$-ACTTGGTGCAGAGTTCAGGG-3' \\
opn & $5^{\prime}$-ATGAGAGCCCTCACACTCCT-3' & $5^{\prime}$-AGATGGGTAAGTAGGCAGCT-3' \\
col1 & $5^{\prime}$-CCAGATTGAGACCCTCCTCA-3' & $5^{\prime}$-GCCGTAGAAGCGCCGATAGGC-3' \\
GAPDH & $5^{\prime}$ TTCACCACCACCATGGAGAAGC-3' & $5^{\prime}$-ATGCAATGCTGTTCTTGCAG-3' \\
\hline
\end{tabular}

TABle 2: The ${ }^{1} \mathrm{H}$ and ${ }^{13} \mathrm{C}$ NMR spectroscopic data of the isolated compound.

\begin{tabular}{|c|c|c|c|}
\hline \multirow{2}{*}{$\mathrm{C}$} & \multicolumn{3}{|r|}{ Lupeol } \\
\hline & ${ }^{*} \delta_{C}$ & $\delta_{C}{ }^{a}$ & $\delta_{H}{ }^{a}$ (mult., $J=\mathrm{Hz}$ ) \\
\hline 1 & 38.88 & 38.87 & $1.68(1 \mathrm{H}, \mathrm{m}) ; 0.90(1 \mathrm{H}, \mathrm{m})$ \\
\hline 2 & 27.43 & 27.43 & $1.68(1 \mathrm{H}, \mathrm{m}) ; 1.57(1 \mathrm{H}, \mathrm{m})$ \\
\hline 3 & 79.05 & 79.03 & $3.19(1 \mathrm{H}, \mathrm{dd}, 5.0 ; 11.0 \mathrm{~Hz})$ \\
\hline 4 & 38.73 & 38.73 & - \\
\hline 5 & 55.33 & 55.33 & $0.69(1 \mathrm{H}, \mathrm{d}, 2.0 \mathrm{~Hz})$ \\
\hline 6 & 18.34 & 18.33 & $1.38(1 \mathrm{H}, \mathrm{m}) ; 1.52(1 \mathrm{H}, \mathrm{m})$ \\
\hline 7 & 34.31 & 34.31 & $1.39(2 \mathrm{H}, \mathrm{m})$ \\
\hline 8 & 40.86 & 40.86 & - \\
\hline 9 & 50.47 & 50.47 & $1.25(1 \mathrm{H}, \mathrm{m})$ \\
\hline 10 & 37.20 & 37.19 & - \\
\hline 11 & 20.95 & 20.95 & $1.25(1 \mathrm{H}, \mathrm{m}) ; 1.40(1 \mathrm{H}, \mathrm{m})$ \\
\hline 12 & 25.17 & 25.18 & $1.05(1 \mathrm{H}, \mathrm{m}) ; 1.66(1 \mathrm{H}, \mathrm{m})$ \\
\hline 13 & 38.08 & 38.08 & $1.66(1 \mathrm{H}, \mathrm{m})$ \\
\hline 14 & 42.86 & 42.85 & - \\
\hline 15 & 27.47 & 27.47 & $1.54(1 \mathrm{H}, \mathrm{m}) ; 1.59(1 \mathrm{H}, \mathrm{m})$ \\
\hline 16 & 35.61 & 35.60 & $1.37(1 \mathrm{H}, \mathrm{m}) ; 1.48(1 \mathrm{H}, \mathrm{m})$ \\
\hline 17 & 43.02 & 43.01 & - \\
\hline 18 & 48.34 & 48.33 & $1.36(1 \mathrm{H}, \mathrm{s})$ \\
\hline 19 & 48.00 & 48.00 & $2.38(1 \mathrm{H}, \mathrm{d}, 6.5 \mathrm{~Hz})$ \\
\hline 20 & 150.98 & 150.98 & - \\
\hline 21 & 29.87 & 29.87 & $1.31(1 \mathrm{H}, \mathrm{m}) ; 1.92(1 \mathrm{H}, \mathrm{m})$ \\
\hline 22 & 40.02 & 40.01 & $1.37(1 \mathrm{H}, \mathrm{m}) ; 1.20(1 \mathrm{H}, \mathrm{m})$ \\
\hline 23 & 28.00 & 27.99 & $0.88(3 \mathrm{H}, \mathrm{s})$ \\
\hline 24 & 15.37 & 15.36 & $0.83(3 \mathrm{H}, \mathrm{s})$ \\
\hline 25 & 16.13 & 16.12 & $0.84(3 \mathrm{H}, \mathrm{s})$ \\
\hline 26 & 16.00 & 15.99 & $1.03(3 \mathrm{H}, \mathrm{s})$ \\
\hline 27 & 14.57 & 14.56 & $0.94(3 \mathrm{H}, \mathrm{s})$ \\
\hline 28 & 18.02 & 18.01 & $0.79(3 \mathrm{H}, \mathrm{s})$ \\
\hline 29 & 109.33 & 109.31 & $4.69(\mathrm{~d}, 2.5 \mathrm{~Hz}) ; 4.56(\mathrm{dd}, 1.5 ; 2.5 \mathrm{~Hz})$ \\
\hline 30 & 19.32 & 19.31 & $1.68(3 \mathrm{H}, \mathrm{s})$ \\
\hline
\end{tabular}

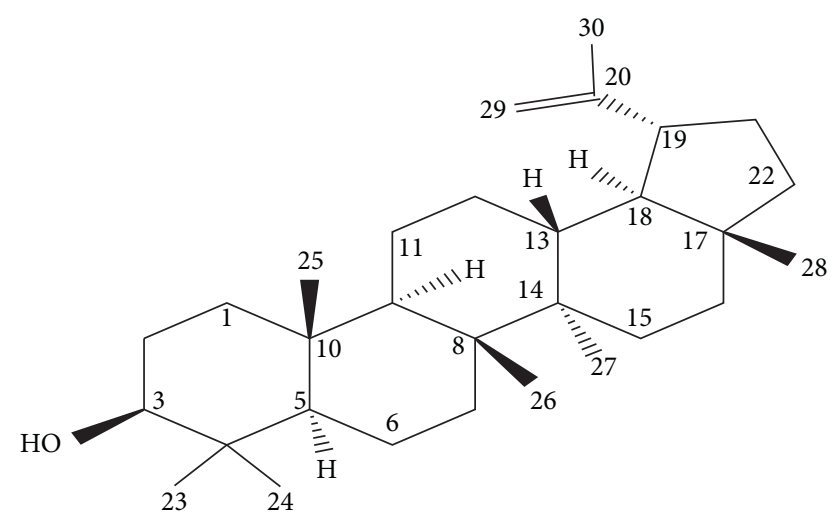

Figure 1: Chemical structures of lupeol $\left(\mathrm{C}_{30} \mathrm{H}_{50} \mathrm{O}\right)$.

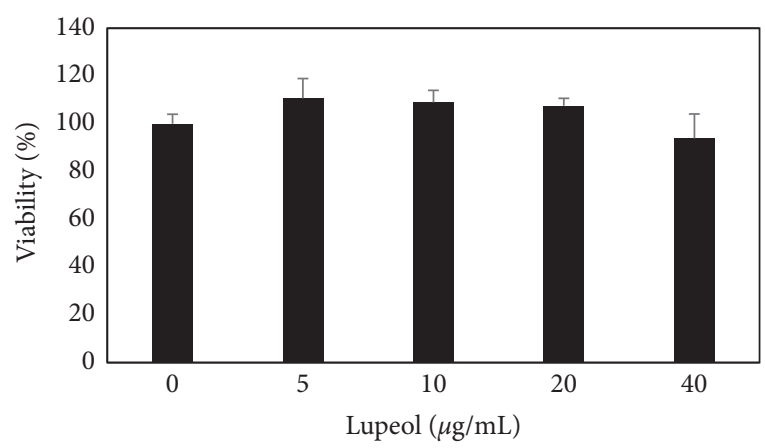

FIgURE 2: Cell viability of MC3T3-E1 cells in the presence of lupeol. MC3T3-E1 cells were seeded in the MEM $\alpha$ medium and then treated with lupeol at different concentrations. After incubation and treatment in $96 \mathrm{~h}$ (4 days), the medium was removed, and the cells were incubated with $5 \mu \mathrm{g} / \mathrm{mL}$ MTT solution for $4 \mathrm{~h}$ at $37^{\circ} \mathrm{C}$ in $5 \% \mathrm{CO}_{2}$. Data of relative cell viability are calculated as percentage compared to the nontreated group (control). Results are presented as mean $\pm \mathrm{SD}, n=3$.

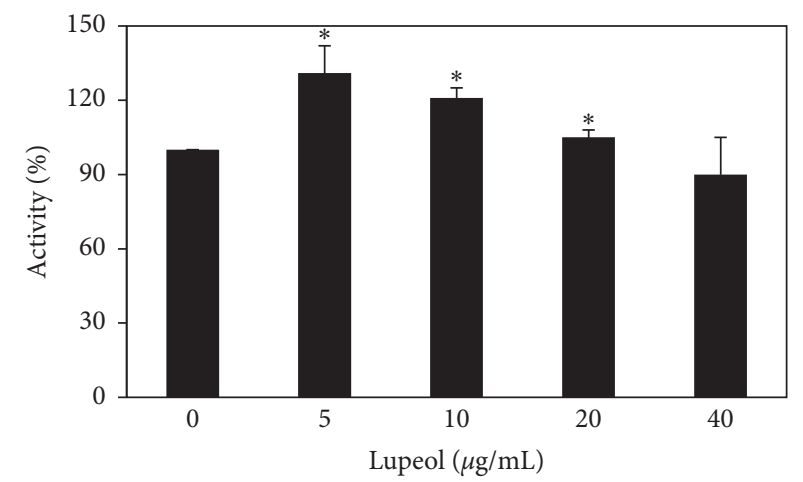

FIgURE 3: Effect of lupeol on the ALP activity of MC3T3-E1 osteoblasts. Results were presented as means \pm SD. MC3T3-E1 cells were seeded in the ODM medium and treated with different concentrations of lupeol. ALP activity data are calculated as percentage compared to the nontreated sample (control). Each value is the average of triplicate cultures, and each bar indicates means $\pm \mathrm{SD}, n=3 ;{ }^{*} p \leq 0.05$.

compound lupeol, a lupane-type triterpene, isolated from the EtOAc active fraction of C. nutans grown in Vietnam was studied on the bone cell osteogenic activity. Previously, lupeol was found to have various valuable bioactivities [16], but its osteogenic activity has not been reported. Recently, Chauhan et al. [17] indicated that stem bark extract of Bombax ceiba ameliorated the state of bone fragility and fracture, possibly due to estrogenic modulation by 


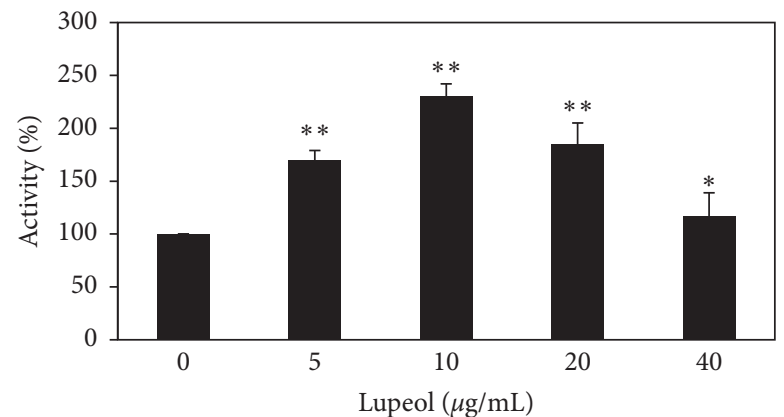

FIGURE 4: Lupeol induced mineralization activity of osteoblast cells MC3T3-E1. Osteoblast cells were cultured in the MEM $\alpha$ medium containing vitamin $\mathrm{C}(50 \mu \mathrm{g} / \mathrm{ml})$ and $\beta$-glycerolphosphate $(10 \mathrm{mM})$ for 21 days with/without lupeol and then stained with $40 \mathrm{mM}$ alizarin red-S ( $\mathrm{pH} 4.2)$ for $1 \mathrm{~h}$. The cells were destained for 15 minutes with $10 \%$ cetylpyridium chloride in $10 \mathrm{mM}$ sodium phosphate buffer ( $\mathrm{pH} 7.0$ ); then, calcium formation was observed and determined spectrophotometrically at $562 \mathrm{~nm}$. The results are calculated as percentage compared to the nontreated sample (control, DMSO). Each value is the average of triplicate cultures, and each bar indicates means \pm SD; ${ }^{*} p \leq 0.05$; ${ }^{* *} p \leq 0.01$.

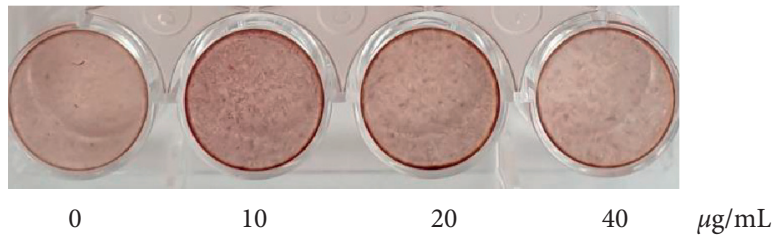

FIgURE 5: Calcium formation during bone mineralization observed in MC3T3-E1 cell culture treated with lupeol. The treated cells were stained with $40 \mathrm{mM}$ alizarin red-S ( $\mathrm{pH}$ 4.2) for one hour and then were washed three times with PBS buffer and observed under microscopy (Zeiss Axio Z1, Germany).

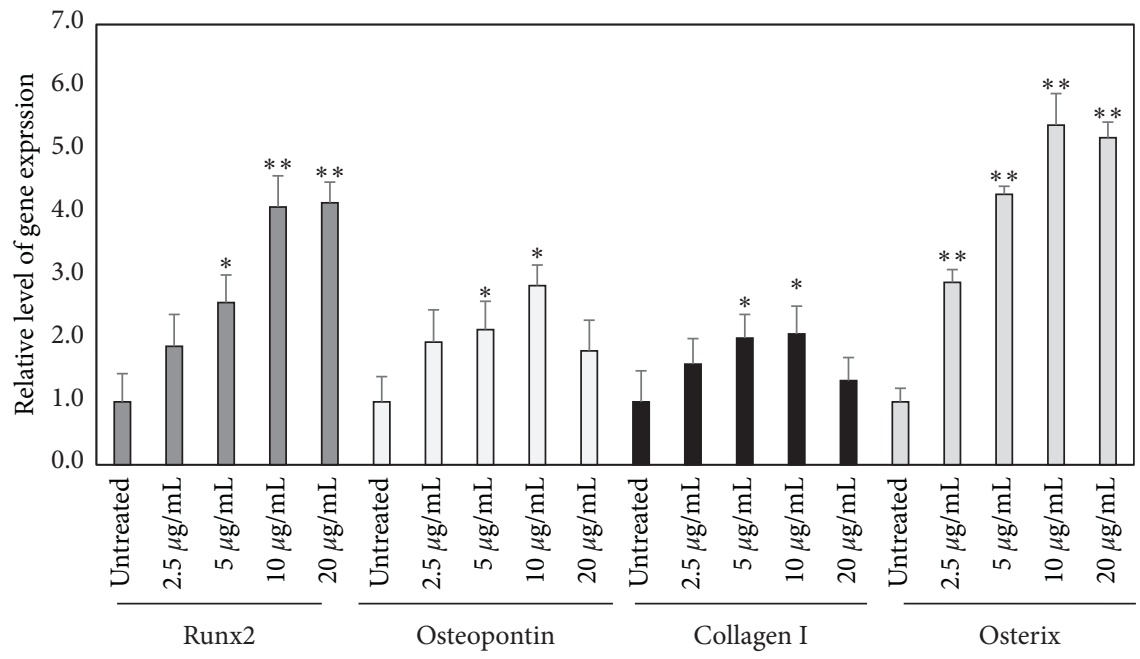

FIGURE 6: Lupeol enhanced expression of several marker genes for osteoblast differentiation. Osteoblast cells were cultured in 6-well plates at a density of $5 \times 10^{5}$ cells $/ \mathrm{mL}$ in each well. Cells were treated with different concentrations of lupeol for 3 days before RNA extraction by using Trizol reagent (Invitrogen, Life Technology). cDNA synthesized using superscript VILO MasterMix kit (Invitrogen, Thermo Fisher Scientific, Netherlands). GAPDH served as a house-keeping gene for normalization of the test genes. Each bar indicates means \pm SD, $n=3$; ${ }^{*} p \leq 0.05 ;{ }^{* *} p \leq 0.01$.

significantly enhancing osteoblast cell proliferation and the ALP activity. Moreover, the antiosteoporotic activity of the extract was also examined in the female rat model. The results suggested that the antiosteoporotic activity of the extract may be due to the presence of compounds lupeol, gallic acid, and $\beta$-sitosterol constituents. Thus, our work presented here is a first report on detailed in vitro evaluation of the osteoblastogenic activity of lupeol isolated from C. nutans grown in Vietnam by examining various important markers for cell differentiation, such as osteoblast 


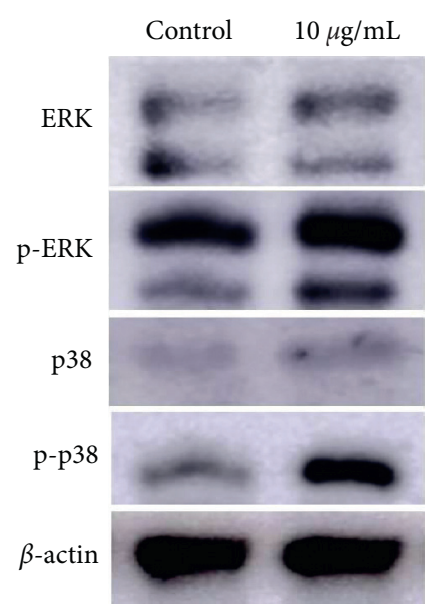

(a)

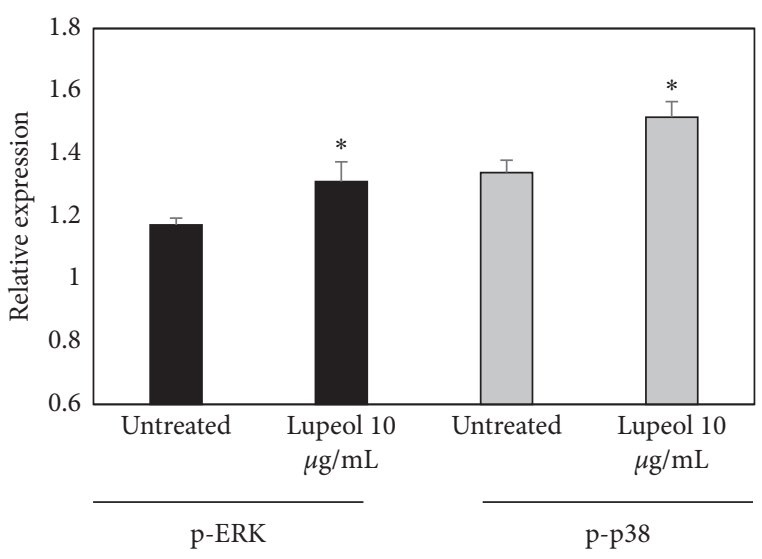

(b)

FIGURE 7: Lupeol enhanced expression of protein markers on the MAPK pathway in MC3T3-E1 cells (a). The data presented for p-ERK and p-p38 were normalized with $\beta$-actin and presented as ratio relative to the area density of ERK and p38, respectively, by using ImageJ software (b). Cells treated with $10 \mu \mathrm{g} / \mathrm{mL}$ lupeol or untreated as the control (untreated). Total proteins were extracted and electrophoresed with equal concentrations for the Western blot analysis. Specific antibodies for proteins in the MAPK pathway, including ERK, p-ERK, p38, and p-p38, were used to detect protein expressions with $\beta$-actin as a loading control. Each bar indicates means $\pm \operatorname{SD} n=3 ;{ }^{*} p \leq 0.05$.

differentiation-associated gene expression levels, the signal pathway of osteoblast differentiation, calcium quantification, ALP assay, and histochemical staining for mineral deposition.

Bone cell differentiation undergoes through three stages: (i) cell growth, (ii) maturation of the substrate, and (iii) mineralization of the substrate. Stage (ii) was determined by the expression of the maximum ALP activity [18]. The enhancement of ALP and mineralization in the osteoblast cells are considered as the two important markers for the osteogenic activity $[19,20]$. ALP is an important component in hard tissue formation, highly expressed in mineralized tissue cells. The mechanism with which this enzyme carries out its function is not completely understood, but it appears to act both to increase the local concentration of inorganic phosphate, a mineralization promoter, and to decrease the concentration of extracellular pyrophosphate, an inhibitor of mineral formation. Mathew et al. [21] and Golub and Boesze-Battaglia [22] showed an evidence which indicated that ALP hydrolyses phosphate substrates releasing $p_{i}$ and is associated with initiation of mineralization. In our experiment, we found that lupeol had a stimulatory effect on the ALP activity, suggesting its role in the mineralization.

The final phase of osteoblast differentiation is mineralization, where mineral matrix containing mainly calcium phosphate in the form of hydroxyapatite is secreted and deposited by mature osteoblasts [22]. In our study, matrix deposition was initiated from the second week of osteoblast differentiation on both untreated and treated cells. Histochemical staining confirmed a significant enhancement of calcium accumulation by cells undergoing osteoblast differentiation. Our data suggested that lupeol induced better mineralization and higher calcium content in the mineral deposits, which are essential for bone healing.

Each phase of cell differentiation is characterized by expression of specific osteoblast differentiation markers.
Collagen (COL1A1) and extracellular matrix protein osteopontin (OPN) appear in the proliferative phase, and the matrix maturation phase is marked by expression of ALP nonspecific enzyme (ALPL), cell-binding sialoprotein (IBSP), and COL1A1. OPN and COL1 are also considered to be the early markers of bone matrix synthesis and are associated with initiation of mineralization due to its association with binding of calcium [22]. Our data revealed a clearly enhanced expressions of all marker genes in lupeoltreated cells and therefore confirmed the promoter role of lupeol in mineralization.

The common mechanism of osteoblast activating is seemly mediated by serine-threonine kinases of the mitogen-activated protein kinase (MAPK) and Smad family [23]. The Smad pathway is a well characterized BMP signaling pathway. However, BMPs also initiate non-Smad interacellular signaling pathways. Several lines of evidence suggested that BMPs activate the MAPK family of signaling molecules, i.e., ERK1/2, p38, and stress-activated protein kinase/Jun N-terminal kinase. Therefore, investigation of the test agent effects on Smad1/5/8 and three different MAPKs such as ERK, JNK, and p38 is necessary. Nguyen et al. [14] reported that osteoblast activating peptide isolated from biodiesel by-products of microalgae Nannochloropsis oculata promoted osteoblast differentiation by increasing expression of several osteoblast phenotype markers such as ALP, osteocalcin, collagen type I, BMP-2, BMP2/4, and bone mineralization in both human osteoblastic cell (MG-63) and murine mesenchymal stem cell (D1). In addition, the purified peptide induced phosphorylation of MAPK and Smad pathway in both cells. These results suggest that peptide possesses positive effects on osteoblast differentiation and may provide possibility for treating bone diseases.

For lupeol, previous studies found its effect on the MAPK pathway. For examples, in keratinocytes, lupeol treatment resulted in the activation of Akt, p38, and Tie-2, 
which are signaling proteins involved in cell proliferation, migration, angiogenesis, and tissue repair [24]. The study suggested that lupeol could have therapeutic potential for accelerating wound healing. In addition, lupeol also was reported as an ERK pathway inhibitor, one of the most crucial pathways in lung cancer metastasis [25]. This study demonstrated for the first time that lupeol exhibited significant and selective antimetastatic effects against lung cancer A549 cells via perturbations in the ERK signaling pathway. Obviously, our study here provided a modest evidence of lupeol as an activator of MAPK signaling. More investigations of lupeol on other important signaling pathways, such as Smad, BMP, and in different cell lines need to be done to confirm its role in modulation of osteoblastogenesis.

In the point of view of the pathogenesis of osteoporosis, it is a complex process with different mechanisms involved. However, there are certain common causes of bone loss and increased fracture risk in aging people, such as genetic factors, illnesses, sex steroid deficiency following the menopause in women and with aging in men, and age-related changes in the bone metabolism. However, the most important causes are corticosteroid use or other illnesses affecting the bone metabolism. Understanding of the pathogenesis of osteoporosis is key information to the development of novel, mechanism-based therapeutic approaches to prevent and treat this disorder. The identification of new agents as activators of RANKL production in the setting of estrogen deficiency will provide a new approach to potently inhibit bone resorption. The key role of Wnt signaling in the bone metabolism and possibly in age-related bone loss will led to the development of specific activators of this pathway in treating osteoporosis. The role of SIRT-1 in skeletal aging may also lead to new compounds as regulators of this pathway as a means to both stimulate bone formation and inhibit bone resorption [26]. In our work here, lupeol is found to be an activator of the MAPK signaling pathway and possibly of others. Therefore, further works on these therapeutic targets are necessary to deeply understand how it modulates molecular targets associated with disease progress, as well as to apply for bone health supplement.

Lupeol was found to display low cytotoxicity in healthy cells and acted synergistically when used in combined therapies, which make it to be employed alone or as adjuvant to clinically used drugs [17]. Thus, the combination of lupeol with other drugs should be tested to enhance its osteogenic activity for an effective therapy. Moreover, what natural substances in the C. nutans extract, beside lupeol, also involve in the bone healing activity and needs further clarification. In addition, more investigations on lupeol pharmacokinetics should be carried out to improve its solubility, absorption, and systemic availability.

\section{Conclusion}

The osteogenic activity of lupeol in MC3T3-E1 cells was intensively investigated for the first time in this study. It enhanced the ALP activity by interacting with important amino acids in the active site of the enzyme. It also strongly increased mineralization in osteoblast. At the molecular level, the compound affects expression of the marker genes and MAPK signaling pathway relating to mineralization and cell differentiation. Our data could be of clinical significance advocating application of lupeol and C. nutans in treating bone fractures.

\section{Data Availability}

The data used to support the findings of this study are included within the article.

\section{Conflicts of Interest}

The authors declare that they have no conflicts of interest.

\section{Authors' Contributions}

PTMN designed the project, supervised, analyzed data, and wrote the manuscript. MTHN performed the experiments, analyzed data, and wrote the manuscript. QVN, HTTN, TVN, and THD performed the experiments and analyzed data. Huong TTN collected and identified the plant. PMQ revised the manuscript. All authors have read and approved the final manuscript.

\section{Acknowledgments}

The authors are highly appreciative of the Vietnam Academy of Science and Technology for financial support under grant VAST04.05/20-21.

\section{Supplementary Materials}

The data in "Supplementary section" are to support the results on isolation and structure characterization of lupeol isolated from C. nutans, including the procedure for isolation of lupeol from the ethyl acetate (EtOAc) fraction and the MS and NMR spectra of the compound. (Supplementary Materials)

\section{References}

[1] T. Sözen, L. Ozisik, and N. Calik Basaran, "An overview and management of osteoporosis," European Journal of Rheumatology, vol. 4, no. 1, pp. 46-56, 2017.

[2] A. Leboime, C. B. Confavreux, N. Mehsen, J. Paccou, C. David, and C. Roux, "Osteoporosis and mortality," Joint Bone Spine, vol. 77, no. 2, pp. 107-112, 2010.

[3] D. K. Khajuria, R. Razdan, and D. R. Mahapatra, "Drugs for the management of osteoporosis: A review," Revista Brasileira de Reumatologia, vol. 51, no. 4, pp. 365-371, 2011.

[4] M. Tabatabaei, P. Salari, P. Khashayar, and B. Larijani, "New horizons in treatment of osteoporosis," Journal of Pharmaceutical Sciences, vol. 25, no. 2, pp. 1-16, 2017.

[5] N. M. A. Nik Abd Rahman, M. Y. Nurliyana, M. N. F. N. N. Afiqah, M. A. Osman, M. Hamid, and M. A. M. Lila, "Antitumor and antioxidant effects of Clinacanthus nutans Lindau in $4 \mathrm{~T} 1$ tumor-bearing mice," BMC Complementary and Alternative Medicine, vol. 19, no. 1, p. 340, 2019. 
[6] Y. K. Yong, J. J. Tan, S. S. Teh et al., "Clinacanthus nutans extracts are antioxidant with antiproliferative effect on cultured human cancer cell lines," Evidence-based Complementary and Alternative Medicine, vol. 2013, Article ID 462751, 8 pages, 2013.

[7] W. Sookmai, T. Ekalaksananan, C. Pientong, S. Sakdarat, and B. Kongyingyoes, "The anti-Papilloma virus infectivity of Clinacanthus nutans compounds," Srinagarind Medical Journal, vol. 26, 2011.

[8] P. Wanikiat, A. Panthong, P. Sujayanon, C. Yoosook, A. G. Rossi, and V. Reutrakul, "The anti-inflammatory effects and the inhibition of neutrophil responsiveness by Barleria lupulina and Clinacanthus nutans extracts," Journal of Ethnopharmacology, vol. 116, no. 2, pp. 234-244, 2008.

[9] S. Y. Shim, I. Aziana, and B. Y. Khoo, "Perspective and insight on Clinacanthus nutans Lindau in traditional medicine," Journal International de Bioethique, vol. 14, no. 1, pp. 7-9, 2013.

[10] M. N. A. Kamarudin, M. M. R. Sarker, H. A. Kadir, and L. C. Ming, "Ethnopharmacological uses, phytochemistry, biological activities, and therapeutic applications of Clinacanthus nutans (Burm. f.) Lindau: a comprehensive review," Journal of Ethnopharmacology, vol. 206, pp. 245-266, 2017.

[11] C. W. Mai, K. S. Yap, M. T. Kho et al., "Mechanisms underlying the anti-inflammatory effects of Clinacanthus nutans Lindau extracts: Inhibition of cytokine production and tolllike receptor-4 activation," Frontiers in Pharmacology, vol. 7, no. 7, pp. 7-11, 2016.

[12] S.-F. Tu, R. Liu, Y.-B. Cheng et al., "Chemical constituents and bioactivities of Clinacanthus nutans aerial parts," Molecules, vol. 19, no. 12, pp. 20382-20390, 2014.

[13] P. T. T. Phuong, N. T. H. Minh, Q. T. Lien, N. T. T. Huong, and N. T. M. Phuong, "Osteogenesis activity of fractions extracted from Clinacanthus nutans (Burm. F.) Lindau," Journal of Biotechnology, vol. 42, no. 2, pp. 85-91, 2020.

[14] M. H. T. Nguyen, Z.-J. Qian, V.-T. Nguyen et al., “Tetrameric peptide purified from hydrolysates of biodiesel byproducts of Nannochloropsis oculata induces osteoblastic differentiation through MAPK and Smad pathway on MG-63 and D1 cells," Process Biochemistry, vol. 48, no. 9, pp. 1387-1394, 2013.

[15] A. T. M. Silva, C. G. Magalhães, L. P. Duarte et al., "Lupeol and its esters: NMR, powder XRD data and in vitro evaluation of cancer cell growth," Braz J Pharm Sci, vol. 53, no. 3, Article ID e00251, 2017.

[16] M. B. C. Gallo and M. J. Sarachine, "Biological activities of lupeol," International Journal of Biomedical and Pharmaceutical Sciences, vol. 3, no. 1, pp. 46-66, 2009.

[17] S. Chauhan, A. Sharma, N. K. Upadhyay, G. Singh, U. R. Lal, and R. Goyal, "In-vitro osteoblast proliferation and in-vivo anti-osteoporotic activity of Bombax ceiba with quantification of Lupeol, gallic acid and $\beta$-sitosterol by HPTLC and HPLC," BMC Complementary and Alternative Medicine, vol. 18, no. 1, p. 233, 2018.

[18] K. Kapinas and A. M. Delany, "MicroRNA biogenesis and regulation of bone remodeling," Arthritis Research \& Therapy, vol. 13, no. 3, p. 220, 2011.

[19] J. An, H. Yang, Q. Zhang et al., "Natural products for treatment of osteoporosis: The effects and mechanisms on promoting osteoblast-mediated bone formation," Life Sciences, vol. 147, pp. 46-58, 2016.

[20] T. M. Ozra, S. Pooneh, K. Patricia, and L. Bagher, "New horizons in treatment of osteoporosis," Daru Journal of Pharmaceutical Sciences, vol. 25, p. 2, 2017.
[21] S. Mathews, P. K. Gupta, R. Bhonde, and S. Totey, "Chitosan enhances mineralization during osteoblast differentiation of human bone marrow-derived mesenchymal stem cells, by upregulating the associated genes," Cell Proliferation, vol. 44, no. 6, pp. 537-549, 2011.

[22] E. E. Golub and K. Boesze-Battaglia, "The role of alkaline phosphatase in mineralization," Current Opinion in Orthopaedics, vol. 18, no. 5, pp. 444-448, 2007.

[23] E. Rodríguez-Carballo, B. Gámez, and F. Ventura, "p38 MAPK signaling in osteoblast differentiation," Frontiers in Cell and Developmental Biology, vol. 4, p. 40, 2016.

[24] F. Pereira Beserra, M. Xue, G. Maia, A. Leite Rozza, C. Helena Pellizzon, and C. Jackson, "Lupeol, a pentacyclic triterpene, promotes migration, wound closure, and contractile effect in vitro: Possible involvement of PI3K/Akt and p38/ERK/MAPK pathways," Molecules, vol. 23, no. 11, p. 2819, 2018.

[25] P. Chowdhury, P. Dey, S. Ghosh, A. Sarma, and U. Ghosh, "Reduction of metastatic potential by inhibiting EGFR/Akt/ p38/ERK signaling pathway and epithelial-mesenchymal transition after carbon ion exposure is potentiated by PARP-1 inhibition in non-small-cell lung cancer," $B M C$ Cancer, vol. 19, no. 1, p. 829, 2019.

[26] S. Khosla and L. C. Hofbauer, "Osteoporosis treatment: Recent developments and ongoing challenges," The Lancet Diabetes \& Endocrinology, vol. 5, no. 11, pp. 898-907, 2017. 